\title{
FORMAÇÃO CONTINUADA E GESTÃO DEMOCRÁTICA: DESAFIOS PARA GESTORES DO INTERIOR DA AMAZÔNIA'
}

\author{
Maria Lília Imbiriba Sousa Colares ${ }^{2}$ \\ Newton Antonio Paciulli Bryan ${ }^{3}$
}

\begin{abstract}
RESUMO: O estudo analisa a importância da formação continuada na expectativa da obtenção de mudanças sociais que passam pela construção e reconstrução do conhecimento. Tem como objeto de análise o Curso de Especialização em Gestão Escolar, vinculado ao Programa Nacional Escola de Gestores da Educação Básica Pública/MEC/SEB, implementado pela Universidade Federal do Oeste do Pará/UFOPA em 2011. Foi realizado por meio de pesquisa bibliográfica e de campo, com exame de questionários e grupo focal com egressos do referido curso, tendo análise sustentada em três eixos temáticos: Formação continuada do gestor escolar pela EAD; Gestão e melhoria de resultados na aprendizagem; e Gestão democrática: dificuldades e possibilidades. Constatou-se que a formação continuada para gestores contribuiu para somar saberes a serem aplicados em sua prática cotidiana. Os sujeitos da pesquisa reconhecem a importância da formação continuada para a concretização de mudanças sociais, na perspectiva da construção de uma escola socialmente referenciada e que os conhecimentos adquiridos no curso também propiciaram melhoria nos resultados da aprendizagem dos estudantes das escolas onde trabalham, considerada não apenas sob a ótica estatística, mas principalmente quanto aos ganhos relacionados com a compreensão dos problemas e da possibilidade de solução colaborativa. Os pesquisados afirmaram que o curso possibilitou aprendizado sobre o que é a gestão democrática, mas reconhecem que sua efetivação nas escolas ainda constitui um desafio.
\end{abstract}

PALAVRAS-ChAVE: Políticas educacionais. Formação continuada. Gestão democrática. Educação a distância.

\section{CONTINUING EDUCATIONANDDEMOCRATIC MANAGEMENT: CHALLENGESFORMANAGERSOF THEINTERIOROF THE AMAZON}

\begin{abstract}
The study analyzes the importance of continuing education in the expectation of obtaining social changes through the construction and reconstruction of knowledge. The object of analysis is the Specialization Course in School Management, linked to the National School of Public Managers Basic Education / MEC / SEB, implemented by the Federal University of Western Para / UFOPA in 2011. The study was performed by means of literature analysis and field survey with questionnaires and focus groups with graduates of that course, having sustained analysis on three themes: Continuing education by the school manager EAD; management and improving learning outcomes and democratic management: problems and possibilities. It was found that continuing education for managers contributed to add knowledge to be applied in their daily practice. The subjects recognize the importance of continuing education to achieve social change from the perspective of building a school socially relevant and that the knowledge acquired in the course also led to improved learning outcomes of students in schools where they work, considered not only the perspective statistic, but mostly about the gains related to the understanding of the problems and the possibility of collaborative solution. The directors surveyed consider that they now know what democratic management is, but recognize that is still a challenge to its implementation in schools.
\end{abstract}

KEYWORDS: Educational policies. Continuing education. Democratic management. Distance education.

\footnotetext{
${ }^{1}$ Pesquisa realizada durante estágio de pós-doutoramento em Educação, na Universidade Estadual de Campinas/SP, com o apoio CAPES/Programa CAPG-BA 060/2011/PROCAD-NF.

2 Mestre e Doutora em Educação pela UNICAMP. Pós-Doutora em Educação pela FE/UNICAMP. Docente do Programa de Pós Graduação em Educação da Universidade Federal do Oeste do Pará. Santarém (PA) - Brasil. Email: lilia.colares@ hotmail.com.

3. Doutor em educação pela UNICAMP e Pós-Doutor pela Universidade de Paris. Docente do Programa de PósGraduação em Educação da UNICAMP. Campinas (SP) - Brasil. E-mail: nbryan@ unicamp.br.
}

Recebido em: 23/10/2013 - Aceito em: 11/04/2014.

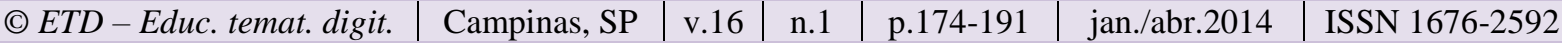




\title{
FORMACIÓN CONTINUA Y GESTIÓN DEMOCRÁTICA: DESAFÍOS PARA DIRECTORES DEL INTERIOR DEL AMAZONAS
}

\begin{abstract}
RESUMEN: El estudio analiza la importancia de la formación continua en la expectativa de obtención de cambios sociales que pasan por la construcción y reconstrucción del conocimiento. Tiene como objeto de análisis el Curso de Especialização em Gestão Escolar, vinculado al Programa Nacional Escola de Gestores da Educação Básica Pública/MEC/SEB, implementado por la Universidade Federal do Oeste do Pará/UFOPA en 2011. Fue realizado por medio de investigación bibliográfica y de campo, con la aplicación de cuestionarios a un grupo focal de egresados del referido curso, teniendo un análisis sustentado en tres ejes temáticos: Formación continua del director escolar por la EAD, gestión y mejoría de los resultados en los aprendizajes y Gestión democrática: dificultades y posibilidades. Se constató que la formación continua para los directores contribuyó para sumar saberes a ser aplicados en su práctica cotidiana. Los sujetos de la investigación reconocen la importancia de la formación continua para la concreción de los cambios sociales, en la perspectiva de la construcción de una escuela socialmente referenciada y que los conocimientos adquiridos en el curso también propiciaron mejorías en los resultados de aprendizaje de los estudiantes de las escuelas donde actúa; considerada no sólo bajo la óptica estadística sino principalmente en cuanto a las ganancias relacionadas con la comprensión de los problemas y las posibilidades de solución colaborativa. Los directores investigados consideran que ahora saben lo que es la gestión democrática, pero reconocen que se constituye en un desafío su efectivización en las escuelas.
\end{abstract}

PALABRAS-CLAVES: Políticas educativas. Formación continua. Gestión democrática. Educación a distancia.

\section{INTRODUÇÃO}

No Brasil foram muitos os debates e expectativas em torno da inserirção das políticas e dos programas de formação no processo global da valorização profissional e da melhoria dos processos de gestão dos sistemas de ensino e das unidades escolares. Assim, a formação continuada tem sido alvo de discussões e pesquisas, permitindo-nos refletir com maior fundamentação a problemática educacional. Os estudos têm revelado que a gestão, quando praticada segundo princípios democráticos que garantam a efetiva participação da comunidade, resulta em melhoria geral da qualidade de todo o trabalho desenvolvido na escola.

A gestão democrática caracteriza-se pelo trabalho coletivo, do qual o conselho de escola se tornou apoio imprescindível. A participação e todos os demais aspectos integrantes da gestão democrática facilitam “[...] a leitura do mundo, que viabilize a interação dos diversos segmentos escolares e comunitários em torno da escola e da educação em geral" (PADILHA, 2001, p.70).

A escola na perspectiva democrática viabiliza espaços de discussão para que todos possam participar da tomada de importantes decisões e das ações de seu cotidiano. Desse modo, estaria como afirma Rodrigues (1997, p. 64) preparando e elevando as pessoas quanto ao “[...] domínio de instrumentos culturais, intelectuais, profissionais e políticos”. A escola democrática tem a possibilidade de formar pessoas críticas e participativas mesmo em uma sociedade capitalista, fazendo-os capazes de lutar para a melhoria de todos os espaços de convívio humano, especialmente os da esfera pública.

(C) ETD-Educ. temat. digit. $\mid$ Campinas, SP $\mid$ v.16 $\mid$ n.1 $\mid$ p.174-191 | jan./abr.2014 | ISSN 1676-2592 
Consoante às questões acima destacadas, buscou-se, neste estudo, verificar como os gestores de escolas públicas de Educação Básica do Oeste do Pará - egressos do Curso de Especialização em Gestão Escolar vinculado ao Programa Nacional Escola de Gestores da Educação Básica Pública/MEC/SEB - percebem a importância da formação continuada como subsídio para a obtenção de mudanças sociais, compreendendo-se que estas passam pela construção e reconstrução do conhecimento, pela via democrática.

A investigação foi realizada por meio de pesquisa bibliográfica e de campo. A reflexão sistematizada sobre o tema ocorreu com a revisão da literatura sobre a formação continuada e gestão democrática no Brasil, pelo exame de documentos do Curso de Especialização em Gestão Escolar, oferecido pelo Instituto de Educação da Universidade Federal do Oeste do Pará/UFOPA, e pela análise dos questionários e realização do grupo focal com os gestores das escolas públicas egressos do referido curso.

Os dados obtidos em campo foram organizados em três eixos temáticos: Formação continuada do gestor escolar pela EAD (educação a distância); Gestão e melhoria de resultados na aprendizagem; e Gestão democrática: dificuldades e possibilidades. Cada um dos eixos é apresentado e discutido neste artigo a partir da fundamentação em estudiosos da área, entre os quais: (ALONSO, 1988); (FERREIRA, 2003; 2004; 2006); (BOBBIO, 2011); (AGUIAR, 2011); (LÜCK, 2011); (MIRANDA; BRYAN, 2011); (GOERGEN, 2013).

Os respondentes dos questionários, que forneceram os dados analisados no texto, foram os gestores ${ }^{4}$ matriculados no curso de especialização, ocorrido no período de março de 2011 a maio de 2012. De um total de 337 alunos que concluíram o curso, 67 gestores de escolas públicas estaduais e municipais do Oeste do Pará responderam aos questionários ${ }^{5}$, o que equivale a $22,12 \%$ dos cursistas. Do grupo focal participaram 17 gestores, tendo a representatividade dos dez polos ${ }^{6}$, ou seja, $5 \%$ dos gestores que terminaram o curso. Devido ao número ampliado de respondentes, neste artigo, optou-se por explicitar apenas alguns depoimentos concernentes aos três eixos estudados.

Inicialmente, será abordada a formação continuada do gestor escolar por meio da EAD, tendo como objeto de análise o Curso de Especialização em Gestão Escolar, uma vez que a política de formação nacional visa a posse pelos gestores do aporte teórico para ajudar na implementação da efetiva gestão democrática nas escolas da Educação Básica Pública. Em

\footnotetext{
${ }^{4}$ Os sujeitos desta pesquisa foram diretores e diretoras de escolas públicas. Serão denominados como gestor 1 , gestor 2, e assim sucessivamente.

${ }^{5}$ Os dados foram colhidos por meio de formulário eletrônico respondido na plataforma Moodle.

${ }^{6 .}$ O total de alunos matriculados no curso foi de 410, sendo distribuídos em dez turmas ou polos.

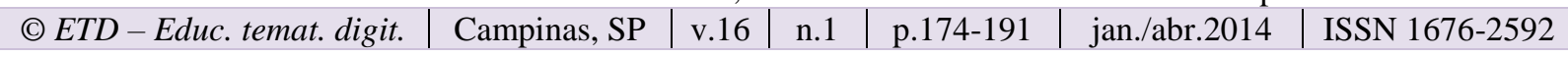


seguida será analisado como os gestores assimilaram os conhecimentos adquiridos no curso para a obtenção da melhoria de resultados na aprendizagem dos estudantes das escolas onde atuam e, para finalizar, as dificuldades e as possibilidades da efetivação da gestão democrática em escolas públicas onde atuam os sujeitos da pesquisa, ou seja, no interior da Amazônia brasileira.

\title{
2 FORMAÇÃo CONTINUADA dO GESTOR ESCOLAR PELA EAD
}

A formação continuada na área educacional ganhou impulso com a regulamentação legal da sua oferta por meio da EAD, devido ao desenvolvimento tecnológico que permite a interatividade e o acompanhamento do processo de aprendizagem. Essa modalidade de ensino vem recebendo maior atenção pelo seu potencial de democratização, podendo atingir um público alvo que dificilmente seria contemplado na modalidade presencial, tanto por causa dos altos custos quanto pela dificuldade de garantir a presença física de professores e estudantes em regiões às vezes de difícil acesso e muito distantes como a maioria das comunidades localizadas no interior da Amazônia brasileira. No entanto, não podemos deixar de atentar para a qualidade desse tipo de formação. De acordo com Ferreira,

\begin{abstract}
A formação continuada é uma realidade no panorama educacional brasileiro e mundial, não só como uma exigência que se faz devido aos avanços da ciência e da tecnologia que se processam nas últimas décadas, mas como uma nova categoria que passou a existir no mercado da formação contínua e que, por isso, necessita ser repensada cotidianamente no sentido de melhor atender a legítima e digna formação humana. (FERREIRA, 2003, p. 19-20, grifos da autora).
\end{abstract}

A formação humana, a que se refere a autora, está relacionada à formação continuada; no entanto deve ser tomada como uma constante capacitação reflexiva, ou seja, não apenas voltada para o mercado de trabalho, mas também à formação geral da coletividade.

Quando questionados sobre quais conhecimentos consideravam imprescindíveis de ser adquiridos em cursos de formação continuada, os gestores responderam:

Gestor 2: Considero imprescindível a um gestor ter conhecimentos e saber que a sua função primordial é garantir a aprendizagem das crianças e jovens, ou seja, que é "a educação, direito de todos e dever do Estado e da família".

Gestor 3: Administração e Matemática Financeira.

Gestor 5: Deve ter conhecimentos sobre as leis da educação; segundo, deve colocar em prática os seus conhecimentos adquiridos e estar atento, inserindo-se nos cursos de especialização continuada em busca de renovar esses conhecimentos.

Gestor 8: Deve agir diante da equipe que está liderando através do diálogo e da flexibilidade. 
Gestor 10: A verdadeira função do gestor como agente principal de transformação social da educação.

Gestor 11: O pedagógico, a parceria e a relação interpessoal.

Podemos notar nas transcrições acima a compreensão dos gestores sobre o papel da formação continuada para seu aperfeiçoamento, porém as respostas revelam fragmentações nas expectativas, ora sendo ressaltado um aspecto pedagógico, ora um aspecto administrativo ou legal, mas aparece também a preocupação com questões mais amplas, tal como observa Goergen (2013, p. 41), ao afirmar que "Deve ser pensada [a formação continuada] sempre na perspectiva do educativo da formação da pessoa" visando o entrelaçamento entre o administrativo, o pedagógico e o financeiro, sem perder de vista a formação humana. De uma forma mais ampliada pode-se afirmar que a formação continuada refere-se às atividades desenvolvidas para o aprimoramento do profissional por meio de cursos diversificados, nos vários níveis e modalidades previstos na estrutura educacional, bem como pela participação em reuniões, congressos, seminários e outras atividades formativas. Segundo Vieira (2011, p. 106), podemos identificar a formação continuada em duas perspectivas:

a) A que visa a formação inicial, a qualificação mínima para o exercício profissional exigido pelos organismos internacionais como critério de qualidade [...].

b) A que visa qualificação ou atualização do profissional em exercício de forma a se manter atualizado frente às novas exigências, que continuamente se renovam. Esta formação pode se constituir desde cursos livres até pós-graduação e tem sido um importante instrumento para determinar os planos de carreira dentro dos sistemas de ensino. (VIEIRA, 2011, p. 106).

No que se refere aos cursos de pós-graduação, mais notadamente os de especialização (lato sensu), GATTI (2008) evidencia que o Brasil acumula uma vasta experiência na oferta tanto na modalidade presencial quanto a distância. É crescente o uso das tecnologias para implementação de cursos de formação continuada em educação, devido à flexibilidade com relação ao horário do profissional que precisa atuar na sua prática e se qualificar concomitantemente.

A formação continuada vem sendo absorvida como uma necessidade nos diversos setores da sociedade, como forma de atender as mudanças constantes que a dinamicidade que o mundo apresenta e nos impõe. Na educação não tem sido diferente. Estudo desenvolvido considerando o governo Lula (2003-2010), aponta que:

[...] vários programas focalizando a gestão escolar e a formação de gestores foram formulados e/ou revisados, a exemplo do Programa Nacional de Formação de Conselheiros Escolares, do Programa Nacional Escola de Gestores da Educação Básica 
Pública, do Programa de Apoio aos Dirigentes Municipais de Educação - Pradime, da

Rede Nacional de Formação Continuada, dentre outros. (AGUIAR, 2011, p. 02).

Ressalte-se que alguns desses programas foram ou ainda são executados por universidades públicas, ou seja, instituições responsáveis pelas formações inicial e continuada. Nas justificativas e nos objetivos da política educacional de formação continuada existe a expectativa de melhoria da qualidade da educação. Essa melhoria passa pelo aprendizado dos fatores que interferem no cotidiano e das formas de enfrentamento dos problemas, na busca de soluções que correspondam aos anseios da coletividade.

Vejamos, a seguir, como alguns dos gestores, ouvidos na pesquisa, se manifestaram sobre as melhorias na prática gestora atribuídas a realização do curso:

GESTOR 6: [...] me deu novo incentivo para continuar a enfrentar os desafios de cada dia e novo embasamento para saber transpô-los.

GESTOR 17: Sim, ao tomar uma decisão lembro-me dos textos, explicações dos professores, mudei totalmente minha maneira de agir, procuro ouvir mais as pessoas e sempre focalizar no que elas pensam, no que é melhor para elas, esquecendo que sou um líder, mas que fazem parte do grupo que sou um deles e quero o melhor para a escola onde trabalho e para a comunidade onde ela está inserida.

GESTOR 20: Percebi as possibilidades que até então estavam adormecidas no dia a dia na escola. E que agora ganham novas proporções e transformam a realidade.

GESTOR 27: Planejar reuniões para organizar através do plano de ação a coordenadoria responsável por cada atividades a serem desenvolvidas no espaço escolar, claro tendo a minha pessoa a frente.

GESTOR 10: O diálogo, compreensão, solidariedade, competência, flexibilidade, a participação, responsabilidade no qual norteará seu trabalho com qualidade.

GESTOR 5: A coletividade, pois através da coletividade é possível resolver situações que no individualismo seria mais complexa de resolvê-las.

GESTOR 15: A preocupação que deverá ter com seus alunos principalmente no que se refere ao processo ensino-aprendizagem.

GESTOR 26: Atividades que se adaptem a projetos voltados para os diversos relacionamentos com alunos, professores, e funcionários em geral.

As falas dos diretores nos recortes acima transcritos confirmam e acentuam a importância e a necessidade de formação continuada, e do papel que as universidades podem desempenhar nesse processo, considerando que essas instituições estão potencialmente em condições de promover a mediação entre os conhecimentos acadêmicos e os saberes adquiridos na prática cotidiana, de tal forma que sejam combinados em proveito da melhoria dos processos de gestão.

A partir da LDB $n^{\circ}$ 9.394/96 foram ampliadas as ações visando atender as exigências do sistema produtivo quanto à qualificação profissional e, também, as necessidades de formação escolar em sentido amplo, levando em conta as diversas dimensões da vida humana. No que 
concerne aos profissionais da educação, sobretudo os que atuam na Educação Básica, propusemos para este estudo o Curso de Especialização em Gestão Escolar, do Programa Nacional Escola de Gestores, por ser realizado na modalidade EAD, e ser voltado para a formação continuada do gestor educacional sob a perspectiva democrática.

De acordo com as Diretrizes Nacionais do Curso, o Programa Nacional Escola de Gestores da Educação Básica Pública integra as ações do Plano de Desenvolvimento da Educação (PDE). Surgido da necessidade de se construir processos de gestão escolar compatíveis com a proposta e a concepção da qualidade social da educação, baseada nos princípios da moderna administração pública e de modelos avançados de gerenciamento de instituições públicas de ensino, buscando assim, qualificar os gestores das escolas da Educação Básica Pública, a partir do oferecimento de cursos de formação a distância. Os dados do Censo Escolar de 2004 apontavam 29,32\% do total de dirigentes escolares do país apenas com formação em nível médio, sobretudo nos estados das regiões Norte, Nordeste e Centro-oeste. O percentual dos dirigentes com formação em nível superior era de $70 \%$, sendo que, destes, apenas $23 \%$ possuíam curso de pós-graduação lato sensu (especialização). (BRASIL, 2007).

O curso de Especialização em Gestão Escolar da Universidade Federal do Oeste do Pará/UFOPA, objeto deste estudo, foi realizado por meio da modalidade educação a distância (EAD), incluindo encontros presenciais. A especialização teve carga horária de 400 horas/ano, distribuídas assim entre as seguintes disciplinas: Introdução ao Ambiente Moodle e ao Curso (40 h); Fundamentos do Direito a Educação (60 h); Políticas e Gestão da Educação (60 h); Planejamento e Práticas de Gestão Escolar (60 h); Tópicos Especiais/Conselhos Escolares (30 h); Oficinas tecnológicas (30 h); Projeto Vivencial (80 h) e TCC (40 h). Foi desenvolvido de março de 2011 a maio de 2012 com a efetivação da matrícula de 410 alunos. O curso foi direcionado à formação de gestores das escolas públicas, como diretores e vice-diretores das redes municipais e estaduais de ensino, sendo realizada em parceria com o MEC, a União Nacional dos Dirigentes Municipais de Educação (UNDIME) - por meio das secretarias municipais de Educação de Santarém e Belterra (SEMED) e Secretaria de Estado de Educação do Pará (SEDUC) por meio da $5^{\text {a }}$ Unidade Regional de Ensino de Santarém/PA. (SANTARÉM, 2010).

A redemocratização da sociedade brasileira, a partir dos anos 1980, e as críticas apresentadas à indicação política como forma de preenchimento da função de diretor fizeram com que novos mecanismos fossem instituídos. No entanto, isso não impediu a manutenção dessa prática em vários estados e municípios do país. Os participantes dessa pesquisa, diretores

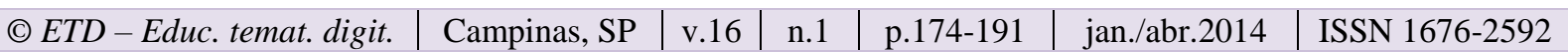


de escolas localizadas em vários municípios do Oeste do Pará, quando perguntados sobre como assumiram o cargo de diretor nas redes de ensino em que atuam, 58,21\% afirmaram ter sido por indicação e $41,79 \%$, por concurso. Como a forma de preenchimento da função de diretor de escola ainda é variável, e na maioria das vezes se dá por indicação política, a formação continuada na perspectiva da gestão democrática pode, ao menos, garantir a reflexão em um coletivo específico da área, sobre os mecanismos que favorecem as práticas participativas e, dessa forma, gradativamente, as escolas possam ter uma gestão democrática, abrindo caminho para a democratização inclusive da forma de escolha do diretor. Vejamos, a seguir, nas repostas dadas por alguns gestores, o que eles destacam como atividades essenciais a serem desenvolvidas pelo Gestor da escola:

GESTOR 6: Reformulação das verdadeiras funções do conselho escolar.

GESTOR 12: Plano do gestor, porque precisam mostrar o que realmente pretendem realizar no seu período de mandato.

GESTOR 8: Gerenciar de perto as atividades da escola.

GESTOR 16: O compartilhamento das ações e decisões da escola.

GESTOR 30: As vantagens de se praticar a gestão democrática é que todos participam e são responsáveis.

GESTOR 22: O exercício da cidadania na demonstração da transparência e a distribuição e responsabilização das atividades.

A partir dos excertos acima podemos inferir que é possível vislumbrar a formação continuada repensando-a diante dos desafios que a sociedade nos impõe, de tal forma que a democracia participativa seja efetivada a partir do comprometimento dos gestores escolares. Para isso faz-se necessário a formação continuada envolvendo múltiplos conhecimentos: "o institucional, o acadêmico e o informal ou tácito", como apontou Bryan (2011, p. 152).

$\mathrm{O}$ conhecimento institucional diz respeito à legislação e à sua aplicabilidade em uma instituição concreta, considerando os princípios e os valores que norteiam a coletividade que a constitui; o conhecimento acadêmico é aquele embasado em teorias e reflexões sistematizadas disponíveis em produtos tais como artigos, livros, etc; quanto ao conhecimento informal, ou tácito, este resulta das aprendizagens pessoais, normalmente oriundas do saber popular e do contato com as situações concretas.

\section{GESTÃO ESCOLAR E MELHORIA DE RESULTADOS NA APRENDIZAGEM}


A gestão escolar constitui uma dimensão e um enfoque de atuação que objetiva promover a organização, a mobilização e a articulação das condições materiais e humanas necessárias para garantir o avanço dos processos sócio-educacionais dos estabelecimentos de ensino, orientados para a promoção efetiva da aprendizagem pelos alunos, de modo a torná-los capazes de enfrentar adequadamente os desafios da sociedade globalizada e da economia centrada no conhecimento. "Qualidade para todos, portanto vai além da meta quantitativa de acesso global, no sentido de que as crianças, em idade escolar, entrem na escola. É preciso garantir a permanência dos que nela ingressarem". (VEIGA, 2006, p. 17).

Nesse sentido, quando questionado sobre os atributos (qualidades, características) que um gestor deve reunir para que seja capaz de realizar um trabalho que proporcione melhores resultados na escola em termos de aprendizagem dos alunos e formação para a cidadania, um dos sujeitos da pesquisa (Gestor 8) apontou como desafios da gestão democrática que aprendeu e está colocando em prática, consolidar o trabalho promovendo valores e hábitos democráticos com participação, confiança e cooperação de todos, pois quando há o ceticismo e o afastamento dos cidadãos dessa esfera, acarreta em atitudes desfavoráveis à democracia. Colocando em prática tais valores e hábitos notou que o desenvolvimento do ensino foi estabelecido, resultando em melhorias na aprendizagem, pois todos os segmentos envolvidos passaram a ter um maior comprometimento com a educação.

O Gestor 32 destacou como fatores para a melhoria da aprendizagem dos estudantes que o curso lhe propiciou: qualificação na área; melhor entendimento sobre disponibilidade e dedicação ao serviço; ser sociável e saber ouvir e compartilhar as necessidades da escola com os demais membros da comunidade escolar; ter competência administrativa e visão de mundo capaz de compreender o outro como sujeito, cidadão, ser em construção.

Observamos nessas e noutras falas não transcritas neste texto que os diretores egressos do curso de especialização em gestão escolar estão cientes da realização do trabalho coletivo tendo por base o diálogo e articulação das ações que contribuam para a melhoria do ensino. Compreendem que compete à gestão escolar mobilizar e mediar ações voltadas para a melhoria de resultados observáveis não apenas em rankings estatísticos, mas fundamentalmente na formação humana ampla voltada para a superação dos problemas que afetam a cada um e a todos, de maneira que as formas de solução sejam resultado de decisões coletivas e amplamente discutidas com base nos conhecimentos institucionais, acadêmicos e tácitos e o alcance das mesmas seja sempre coletivo, mesmo quando destinadas a um caso particular. Por isso a importância de manter a participação da comunidade na organização do trabalho pedagógico,

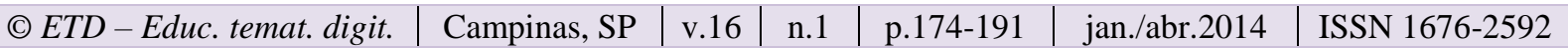


com intuito de que todos possam aprender que a compreensão de si mesmo e da sociedade são requisitos para a prática da cidadania que incorpore os princípios da democracia participativa.

Para o Gestor 44 um novo conhecimento básico adquirido foi o de que o gestor é o primeiro responsável e tem obrigação de garantir que os estudantes aprendam. "E isso é básico. Se o gestor não assume essa tarefa de garantir a aprendizagem das crianças e jovens, não sabe e nem compreendeu seu papel dentro da comunidade escolar.".

Destaca-se na fala dos diretores que os conhecimentos adquiridos os levaram a rever as questões relacionadas à gestão do cotidiano escolar. Para desenvolver uma gestão com perspectiva democrática deve haver esforços coletivos para o implemento dos fins da educação, assim como a compreensão e aceitação do princípio de que a educação é um processo de emancipação humana.

Destaca-se assim a relação teoria e prática, tendo a formação continuada dos profissionais da educação essa associação entre a teoria e a prática, pois,

[...] os saberes profissionais são saberes trabalhados, saberes laborados, incorporados no processo de trabalho docente, que só têm sentido em relação às situações de trabalho e que é nessas situações que são construídos, modela dos e utilizados de maneira significativa pelos trabalhadores. (TARDIF, 2000, p.11).

Nesse contexto o Gestor 2 afirmou que o curso proporcionou conhecimentos em como trabalhar na gestão escolar com humanismo, caráter, discernimento. "Decência, compromisso, amor pela educação e com o público que trabalha, pois o gestor possui o poder de influenciar os seus companheiros a fazerem o certo ou o errado, depende do seu caráter ético com a sociedade." O Gestor 30 mencionou que teve a oportunidade de discutir mais sobre gestão escolar e como é fundamental proporcionar melhores acompanhamentos no âmbito escolar.

Ressalte-se que o gestor, em sua trajetória, constrói e reconstrói seus conhecimentos conforme a necessidade de sua utilização, suas experiências, seus percursos formativos e profissionais. Nesse sentido, Tardif (2002) argumenta que se deve levar em conta o conhecimento do trabalho dos professores, seus saberes cotidianos. As pesquisas sobre formação de professores têm destacado a importância da análise de questão da prática pedagógica como algo relevante, opondo-se assim às abordagens que procuravam separar formação e prática cotidiana.

Dessa forma, resgata a importância de se considerar o professor em sua própria formação, num processo de autoformação, de reelaboração dos saberes iniciais em confronto com a prática vivenciada por ele. Assim os saberes dele vão se constituindo a partir de uma reflexão na e sobre 
a prática. Essa tendência reflexiva vem se apresentando como um novo paradigma na formação continuada, sedimentando uma política de desenvolvimento pessoal e profissional dos que integram a educação e instituições escolares.

Nesse sentido, o curso possibilitou, de acordo com as falas dos egressos, fundamentar os participantes nas bases da concepção de gestão democrática, possibilitando a problematização da educação tradicional e a compreensão da importância da participação da comunidade escolar no processo educacional como forma de garantir a qualidade socialmente referenciada.

\section{GESTÃO DEMOCRÁTICA: DIFICULDADES E POSSIBILIDADES}

A gestão democrática da escola pública, exigência legal desde a Carta Magna de 1988, e já preconizada pelos educadores nas lutas memoráveis contra o Regime Militar instalado em 1964, ainda não constitui regra e se depara com diversas dificuldades para que se concretize. Por outro lado, muitas experiências bem-sucedidas demonstram que é possível sua efetivação até mesmo em locais historicamente dominados por práticas autoritárias e clientelistas. Mas para isso se faz necessário o aprendizado da democracia e o compromisso com a realização de atividades que favoreçam a participação coletiva. Nesse sentido, Bobbio (2011, p. 30), esclarece como "[...] único modo de se chegar a um acordo quando se fala em democracia [...] é construí-la caracterizada por um conjunto de regras (primárias ou fundamentais) que estabelecem quem está autorizado a tomar as decisões coletivas e com quais procedimentos".

Considerando que o curso de Especialização em Gestão Escolar da Universidade Federal do Oeste do Pará/UFOPA teve entre seus objetivos propiciar o aprendizado da gestão democrática, considerando as dificuldades e as possibilidades para sua implantação, neste item serão demonstradas as percepções de egressos como forma de identificar as aprendizagens propiciadas pela formação continuada quanto a esse princípio fundamental para a viabilização do ideário de uma escola pública de qualidade que respeite a identidade e as aspirações das pessoas e dos grupos que a constituem socialmente.

Um dos participantes do grupo focal (Gestor 9) destacou que na especialização teve oportunidade para rever o conceito de gestão democrática, pois até então não estava claro sua importância e assegura: "Hoje, com certeza a minha prática profissional mudou e sinto-me bem mais preparado para lidar com as situações rotineiras da gestão na escola”. Outro participante (Gestor 24) destacou o aprendizado, "que o diretor não é o centro de tudo e sim o aluno e as demais pessoas envolvidas no processo". 
Outras falas acentuam as aprendizagens da gestão democrática na medida em que revelam que "ficou mais claro principalmente as inúmeras formas que o Conselho Escolar pode auxiliar na realidade escolar, fortalecendo a gestão democrática" (Gestor 36), "aprimorou e acrescentou conhecimentos em relação à gestão democrática como por exemplo, a efetivação das atribuições e funções do conselho escolar e do projeto político pedagógico como mecanismos democráticos". (Gestor 3).

De um modo geral os egressos demonstraram ter ampliado seus conhecimentos sobre gestão democrática. Sabe-se, no entanto, que essa forma de gestão exige mais do que uma simples mudança nas estruturas organizacionais e requer a quebra de paradigmas que fundamentem as concepções de sociedade e de educação, com vistas a construção de uma nova proposta educacional e o desenvolvimento da gestão com participação dos envolvidos no processo educativo. Como assevera Cury (2002, p. 165), "a gestão implica o diálogo como forma superior de encontro das pessoas e solução dos conflitos".

Tais observações correspondem a uma clara compreensão da relação central entre a formação continuada de gestores escolares e o avanço da qualidade do ensino, da realização e do fortalecimento da gestão democrática da educação pública. Entendemos, por conseguinte, que a escola tem um papel fundamental para que possamos avançar na efetiva gestão democrática, em todos os espaços coletivos.

Ainda no grupo focal, os egressos revelaram outras aprendizagens propiciadas pelo curso quanto à gestão democrática. O Gestor 4 relatou que toma decisões ouvindo a opinião de cada um dos interessados e que a equipe gestora só decide sem a comunidade em situações que não gere prejuízos a ninguém. O Gestor 10 esclareceu que não toma decisões isoladas, pois sempre ouve a equipe gestora (constituída pelo próprio Gestor, o vice-diretor, pedagogo e secretário) e que também conta com o apoio do Conselho Escolar.

Trabalhar em uma perspectiva democrática torna-se desafiador, considerando a especificidade do sistema educacional e das pessoas envolvidas nesse processo, e essencial para a melhoria da qualidade da educação e a democratização do ensino público. Nessa perspectiva a boa relação entre o gestor e a comunidade escolar é imprescindível. É importante possibilitar que o ambiente escolar seja propício e aberto para que a comunidade sinta-se estimulada a participar. Alonso (1988, p. 11) destaca que o gestor possui papel fundamental na organização do processo de democratização escolar e no "repensar a escola como um espaço democrático de troca e produção de conhecimento". Pela articulação do gestor com a comunidade é possível também 
criar alternativas, elaborar e pôr em prática projetos que favoreçam a participação coletiva no enfrentamento das situações - problemas que se apresentam no cotidiano das escolas.

A autonomia foi apontada nas falas dos sujeitos da pesquisa como fator preponderante para a efetivação da gestão democrática, pois acreditam que sem esta não há perspectiva de mudança no âmbito educacional.

Relacionar gestor, escola, comunidade é identificar o gestor como articulador, tornando o ambiente escolar propício para que a comunidade em geral sinta-se estimulada a participar das atividades, fazendo da escola um ambiente de formação de cidadãos críticos e atuantes. Pela articulação do gestor com a comunidade é possível criar alternativas, elaborar e executar projetos que propiciem melhorias diversas para a comunidade escolar. Como afirmou o Gestor 9:

Um bom gestor é aquele que articula ideias, o saber ouvir, e o saber escutar, porque sabe-se que o ouvir é diferente do saber escutar. Hoje a gestão democrática tem como preocupação os números, mas e a qualidade do ensino onde está? E pra ser um bom gestor ele tem que ter números bons, mas tem que mostrar qualidade, não adianta só termos na teoria e na prática fazermos outras coisas.

Este é um tempo de mudanças, a gestão democrática traz consigo o rompimento do paradigma centralizador, em que a figura do gestor era ou é ainda vista como a do detentor de poderes tomando decisões isoladas. Mesmo com um novo paradigma posto, existem dificuldades para que a gestão democrática se efetive na escola. O Gestor 4 relatou as dificuldades e como superá-las, enfatizando a falta de conscientização tanto dos pais quanto dos funcionários sobre a importância de participar, colaborar, sugerir, opinar e trabalhar em conjunto e compromissado para melhorar o funcionamento da escola. "Para enfrentar e superar essas dificuldades precisa de diálogo, autonomia, determinação, estímulos e estratégias para envolver e conquistar a comunidade escolar."

Outra dificuldade, de acordo com o Gestor 10, diz respeito à burocracia dos órgãos públicos para resolver problemas administrativos, e a falta de autonomia em situações que requerem o apoio da Secretaria Municipal de Educação (SEMED).

Além das questões mencionadas, foi citada ainda pelo Gestor 22 que o maior entrave é a humana. "A dificuldade que as pessoas ainda têm de lidar com a democracia, de entender que ser democrático não é permitir que se faça o que quer, na hora que quer.” Considera que somente o tempo e a convivência entre as pessoas é que vão legitimar novas práticas que assegurem a democracia com responsabilidade coletiva.

A escola, no processo de construção da sua autonomia, conforme dito por Lück (2011) precisa agir no sentido de criar mecanismos sólidos para sua democratização, e desenvolvimento 
da consciência e responsabilidade social e competência para exercê-la. Partindo desse princípio, a escola posiciona-se como responsável, porém não a única, pela formação de cidadãos pensantes e críticos/reflexivos, agentes multiplicadores da democracia. Trata-se de um desafio, porém pensar assim é essencial para que os gestores consigam solucionar problemas de forma coletiva, buscando compreender as contradições presentes no cotidiano escolar e os determinantes objetivos e subjetivos que fundamentam o trabalho pedagógico.

É importante que sejam criados mecanismos que auxiliem no processo ensinoaprendizagem, e que sejam estabelecidas ações para a formação continuada, tais como o curso de especialização em gestão escolar para que o gestor trabalhe coletivamente, envolvendo os integrantes da escola, para que esta se torne um ambiente plural e democrático. No entanto, torna-se necessário que se implante na escola uma gestão democrática em todas as suas dimensões e perspectivas para que as pessoas tenham consciência de seu papel na tomada de decisões e compreendam a dinâmica de construção do conhecimento, para o aprimoramento do processo de ensino-aprendizagem. Tudo isso visando à garantia do sucesso da aprendizagem e ao desenvolvimento continuado de todos os envolvidos no ambiente escolar.

Quando questionados sobre o conselho escolar, apontaram, por unanimidade, tratar-se de um instrumento essencial para a gestão democrática.

GESTOR 30: As tomadas de decisões são compartilhadas envolvendo, pais, alunos,
professores, funcionários e outras pessoas da comunidade na administração escolar.

GESTOR 35: Trabalhamos em conjunto com o conselho escolar e comunidade.

GESTOR 44: As decisões tomadas na escola são a partir das reuniões do Conselho Escolar, onde todos os segmentos presentes participam, efetivamente, das decisões contribuindo assim para a criação de um novo cotidiano escolar.

GESTOR 67: Hoje as decisões são tomadas em conjunto com a comunidade escolar.

No grupo focal a temática relativa ao conselho escolar foi a mais instigante e merecedora da atenção dos cursistas, embora apenas 23 dos 337 concluintes do curso tenham desenvolvido o trabalho de conclusão sobre o funcionamento e outros aspectos da relação entre gestão democrática e conselho escolar. Os diretores apontaram no grupo focal que gerir recursos financeiros é mais fácil que gerir recursos humanos e uma das integrantes do grupo, acrescentou:

[...] em diversos momentos há contradições, e trazer para a prática a democracia é mais difícil, e é nesse momento que o curso veio nos ajudar a democratizar o espaço escolar através do conselho escolar. No meu caso que sou formada há muitos anos, me ajudou como uma atualização, assim como a convivência com outros gestores pra ter noção de como vai caminhando a nossa educação hoje, a falta da autonomia da escola, a luta da gestão dentro da escola, principalmente da escola pública, no caso a estadual, pra desenvolver uma gestão democrática esbarrando em alguns empecilhos na questão da 
autonomia. Surgiram diversas discussões valorosas para o dia a dia, trocas de experiências, para repensar algumas praticas nossas (GESTOR 17).

A efetiva compreensão do conselho escolar e como este pode auxiliar na gestão democrática leva a repensar as práticas atuais que limitam o desenvolvimento da escola no que se refere à participação coletiva. Formar cidadãos críticos pensantes da realidade em que vivemos, é como construir pilares para uma sociedade almejada que seja capaz de produzir outra realidade, potencializadora das capacidades individuais sem com isso criar individualidades, e dinamizadora de processos coletivos sem que fiquem restritos a interesses de grupos isolados.

A escola atua para a efetivação da democracia, mas esta não é uma tarefa apenas sua. Uma escola democrática precisa ter autonomia e saber exercê-la com responsabilidade. Para isso deve estar aberta a críticas e realizar uma constante autoavaliação. O gestor tem papel essencial nesse processo, na medida em que seja capaz de liderar e mobilizar as pessoas, saber agir em diversas situações, incorporar de fato o projeto da escola, assegurar a participação democrática (ouvindo antes de decidir), saber avaliar e deixar-se avaliar, e quebrar paradigmas quando necessário. E o mais importante é acreditar que todos os envolvidos na gestão democrática se encontram num contínuo processo de desenvolvimento e aprendizagem.

Os gestores apontam o curso de especialização como uma atualização de conhecimentos, como um ambiente favorecedor da reflexão de suas práticas, buscando saídas para os conflitos que aparecem no dia a dia com relação às dificuldades encontradas e as limitações que se apresentam no cotidiano escolar. Nesse sentido o curso para esses gestores, além de atualizá-los somou saberes para serem aplicados em suas práticas cotidianas.

A formação continuada proporcionou aos egressos do curso de especialização várias reflexões significativas em torno da gestão escolar, de forma que poderão ampliar sua compreensão no que diz respeito à gestão democrática, oportunizando trocas de experiência com outros gestores, aumentando assim as possibilidades de mudança na realidade educacional.

\section{CONSIDERAÇõES FINAIS}

As leituras que fundamentaram esta pesquisa apontam que a gestão democrática na escola viabiliza espaços de discussões para que todos possam participar da tomada de decisões. A pesquisa empírica, que incluiu o uso de questionários, análise de documentos e realização de grupo focal, revelou que a formação continuada dos gestores, por meio da educação a distância, propicia reflexões coletivas fundamentais para a compreensão dos problemas do cotidiano e a 
superação destes de forma participativa. Todavia, realizar a gestão democrática nas escolas públicas, mesmo já decorridos 25 anos de sua inclusão no texto da Constituição Federal, ainda constitui um desafio para os gestores.

Os sujeitos da pesquisa, gestores de escolas públicas de Educação Básica do Oeste do Pará, egressos do curso vinculado ao Programa Nacional Escola de Gestores da Educação Básica Pública, reconhecem a importância da formação continuada para a concretização de mudanças sociais, na perspectiva da construção de uma escola socialmente referenciada. Os conhecimentos adquiridos no curso também propiciaram melhoria nos resultados da aprendizagem dos estudantes das escolas onde trabalham, considerada não apenas sob a ótica estatística, mas principalmente quanto aos ganhos relacionados com a compreensão dos problemas e da possibilidade de solução colaborativa.

Acredita-se que a articulação das relações entre teoria e prática, nos cursos de formação continuada, centrando as análises nos problemas concretos e procurando identificar quais conhecimentos são desenvolvidos no gestor ao atuar nas condições mais adversas, possibilitam o desenvolvimento da capacidade reflexiva, e o desenvolvimento do espírito de pesquisador que favorece a compreensão da realidade e o compromisso com a democratização da educação.

A partir da análise da realidade escolar em que convivem, os gestores tiveram a oportunidade de perceber que o projeto pedagógico da escola é norteador de todas as ações, e evidencia possibilidades de mudanças no contexto escolar. Nesse sentido, ao se debruçarem sobre essa realidade, puderam colocar em pauta discussões de temáticas como gestão democrática, conselho escolar, participação da família, frequência escolar, o papel do gestor escolar, temas transversais, avaliação institucional entre outros, que além de contribuírem para seu processo de reflexão/ação como acadêmicos do curso de especialização e como profissionais, possibilitou também estenderem aos demais membros da escola o despertar para situações relevantes que muitas vezes são pouco consideradas no ambiente escolar.

A gestão democrática traz consigo o rompimento do paradigma centralizador, em que o gestor detém poderes individualizados. Conforme mencionou Lück (2011), não se pode pensar em construir a autonomia da escola sem agir no sentido de criar mecanismos sólidos para a democratização dela e para o desenvolvimento da consciência e responsabilidade social, bem como de competência para exercê-la. No entanto, é importante acentuar que a descentralização não se restringe ao gestor.

Neste estudo constatamos a importância da gestão escolar democrática para a formação de cidadãos participativos e conhecedores de suas responsabilidades. A formação continuada

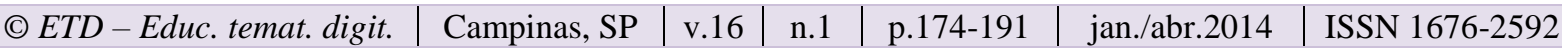


para gestores contribuiu para somar saberes que já estão sendo aplicados em suas práticas cotidianas e colaborou para a melhoria da qualidade da educação relacionada à democratização do ensino público, sem ser confundida com a simples elevação de índices estatísticos.

\section{REFERÊNCIAS}

AGUIAR, Márcia Ângela da Silva. Formação em gestão escolar no Brasil nos anos 2000: políticas e práticas. RBPAE, Porto Alegre, , v.27, n.1, p. 67-82, jan./abr. 2011.

ALONSO, M. O papel do diretor na administração escolar. Rio de Janeiro: Bertand Brasil, 1988.

BOBBIO, Norberto. O futuro da democracia. 12 ed., São Paulo: Paz e Terra, 2011.

BRASIL. Constituição. Constituição da República Federativa do Brasil. Brasília: Centro Gráfico do Senado, 1988.

BRASIL. Lei no 9.394, de 20 de dezembro de 1996. Estabelece as Diretrizes e Bases da Educação Nacional. Diário Oficial da República Federativa do Brasil, Brasília, ano 134, n. 248, 23 dez. 1996. p. 27.833-27.841.

BRASIL. Ministério da Educação. Programa Nacional Escola de Gestores da Educação Básica. Curso de especialização em gestão escolar lato sensu. 2007. Disponível em $<$ http://portal.mec.gov.br/index.php?option=com_content\&view=article\&id=13515\&Itemid=944 $>$ Acesso em: 21, maio, 2009.

BRYAN, Newton Antonio Paciulli. Planejamento, conhecimento e gestão educacional. In: MIRANDA, Estela M.; BRYAN, Newton Antonio Paciulli. (Org.). (RE)pensar la educacion publica: aportes desde Argentina y Brasil. Córdoba: Universidad Nacionalde Córdoba/Ar, 2011. p. $151-160$.

CURY, Carlos Roberto Jamil. Gestão democrática da educação: exigências e desafios. Revista Brasileira de Política e Administração da Educação. Associação Nacional de Política e Administração da Educação. São Bernardo do Campo, v.18, n.2, jul./dez., 2002.

FERREIRA, Naura Syria Carapeto. Formação continuada e gestão da educação no contexto da "cultura globalizada". In: Formação continuada e gestão da educação. FERREIRA, Naura Syria Carapeto. (Org.). São Paulo: Cortez, 2003.

FERREIRA, Naura Syria Carapeto. Repensando e ressignificando a gestão democrática da educação na "cultura globalizada". Educação e Sociedade. Campinas, v. 25, n. 89, p. 1227 1249, set. 2004. Disponível em: 〈http://www.cedes.unicamp.br>. Acesso em: 10 set. 2013.

FERREIRA, Naura Syria Carapeto. Gestão educacional e organização do trabalho pedagógico. Curitiba: IESDE, 2006. 
GATTI, Bernardete Angelina. Análise das políticas públicas para formação continuada no Brasil, na última década. Revista Brasileira de Educação, Rio de Janeiro, v.13, n.37, p. 57-70, jan. 2008.

GOERGEN, Pedro. Gestão educacional: entre instrumentalização e formação. Revista Exitus. Santarém (PA) v. 03, n. 01, p. 35-46, jan. 2013.

LÜCK, Heloísa. Liderança em gestão escolar. 6 ed. Petrópolis, RJ: Vozes, 2011.

TARDIF, Maurice. Saberes profissionais dos professores e conhecimentos universitários: elementos para uma epistemologia da prática profissional dos professores e suas consequências em relação à formação para o magistério. Revista Brasileira de Educação, Rio de Janeiro, p. 524, jan, 2000.

TARDIF, Maurice. Saberes docentes e formação profissional. Petrópolis, RJ: vozes, 2002.

PADILHA, Paulo Roberto. Planejamento dialógico: como construir o projeto políticopedagógico da escola. São Paulo: Cortez, 2001.

SANTARÉM, Escola de Gestores. Projeto pedagógico do curso de especialização em gestão escolar. Santarém: UFOPA, 2010.

RODRIGUES, Neidson. Por uma nova escola: o transitório e o permanente na educação. 11 ed. São Paulo: Cortez, 1997.

VEIGA, Ilma Passos Alencastro. Projeto político pedagógico da escola: uma construção possível. 22 ed. Campinas, SP: Papirus, 2006.

VIEIRA, Marcelo Pustilnik de Almeida. A EaD nas políticas de formação continuada de professores. Campinas,SP. 2011. Tese (Doutorado em Educação) - Faculdade de Educação, Universidade Estadual de Campinas, Campinas, SP.

\section{Como citar este documento:}

COLARES, Maria Lilia Imbiriba Sousa; BRYAN, Newton Antonio Paciulli. Formação continuada e gestão democrática: desafios para gestores do interior da Amazônia. ETD - Educ. temát. digit., Campinas, SP, v. 16, n. 1, p. 174-, jan./abr. 2014. ISSN 1676-2592. Disponível em:

<http://www.fae.unicamp.br/revista/index.php/etd/article/view/5550>. Acesso em: 30 abr. 2014. 